\title{
DOSES DE FÓSFORO E DE CAMA-DE-FRANGO NA PRODUÇÃO DE BARDANA'
}

\author{
Doses of phosphorus and chicken manure on burdock yield
}

\author{
Rosimeire Pereira Gassi², Néstor Antonio Heredia Zárate ${ }^{3}$, Maria do Carmo Vieira ${ }^{4}$, \\ Silvana de Paula Quintão Scalon ${ }^{5}$, Jean Kleber de Abreu Mattos ${ }^{6}$
}

\begin{abstract}
RESUMO
Conduziu-se este experimento, com o objetivo de avaliar o efeito da incorporação ao solo de fósforo (P) e de cama-de-frango (CF) sobre o crescimento e a produção da bardana. Estudaram-se cinco doses de $\mathrm{P}\left(4,3 ; 25,8 ; 43,0 ; 60,2\right.$ e 81,7 $\left.\mathrm{kg} \mathrm{ha}^{-1}\right)$ e cinco doses de CF $\left(1 ; 6 ; 10 ; 14\right.$ e $\left.19 \mathrm{t} \mathrm{ha}^{-1}\right)$ perfazendo nove tratamentos, definidos por meio da matriz experimental PLAN PUEBLA III, dispostos no delineamento experimental blocos casualizados, com quatro repetições. A altura máxima $(129,87 \mathrm{~cm})$ foi alcançada aos 113 dias após o transplante, com o tratamento de 60,2 e $14 \mathrm{t} \mathrm{ha}^{-1}$ de $\mathrm{P}$ e CF, respectivamente. As maiores produções de massa fresca das folhas foram de 22,87 $\mathrm{Mg} \mathrm{ha}^{-1}$, quando se utilizou 81,7 $\mathrm{kg} \mathrm{ha}^{-1}$ de P e de 18,38 $\mathrm{Mg} \mathrm{ha}^{-1}$ com a dose de $19 \mathrm{t}^{-1} \mathrm{de} \mathrm{CF}$. As maiores produções de massa seca das folhas ocorreram sob as maiores doses de CF. As maiores produções de massas frescas de raízes foram de 2,44 Mg ha ${ }^{-1}$ e 2,00 $\mathrm{Mg} \mathrm{ha}^{-1}$, alcançadas com os tratamentos 81,7 $\mathrm{kg} \mathrm{ha}^{-1}$ de P e $1 \mathrm{t} \mathrm{ha}^{-1}$ de CF e 4,3 kg ha $\mathrm{de} \mathrm{Pe} 19 \mathrm{tha}^{-1} \mathrm{de} \mathrm{CF}$, respectivamente. A maior produção de massa seca de raiz foi $0,33 \mathrm{Mg} \mathrm{ha}^{-1}$ obtida com o uso das maiores doses de fósforo e doses intermediárias de CF.
\end{abstract}

Termos para indexação: Planta Medicinal, Arctium lappa, adubação, resíduo orgânico.

\begin{abstract}
The aim of this study was to evaluate the effect of incorporating phosphorus $(\mathrm{P})$ and chicken manure $(\mathrm{CM})$ to the soil on the growth and yield of burdock. Five doses of phosphorus $\left(4.3,25.8,43.0,60.2\right.$, and $\left.81.7 \mathrm{~kg} \mathrm{ha}^{-1}\right)$ in triple super phosphate (TSP) form and five doses of semi-decomposed chicken manure $\left(1,6,10,14\right.$, and $\left.19 \mathrm{t} \mathrm{ha}^{-1}\right)$ were studied. Nine treatments were defined using Plan Puebla III experimental matrix. Treatments were arranged in a randomized block experimental design with four replications. Maximum height of burdock $\left(129.87 \mathrm{~cm}\right.$ ) was reached on the 113th day after transplant (DAT) with 60.2 and $14 \mathrm{t} \mathrm{ha}^{-1}$ of phosphorus and chicken manure treatments, respectively. The greatest yields of leaf fresh matter were $22.87 \mathrm{Mg} \mathrm{ha}^{-1}$ when $81.7 \mathrm{~kg}^{-1} \mathrm{P}$ was used and $18.38 \mathrm{Mg} \mathrm{ha}^{-1}$ with dose of $19 \mathrm{t} \mathrm{ha}^{-1} \mathrm{CM}$. The highest yields of leaf dry matter were related to the highest doses of chicken manure. The greatest yields of root fresh matter were $2.44 \mathrm{Mg} \mathrm{ha}^{-1}$ and $2.00 \mathrm{Mg} \mathrm{ha}^{-1}$, which were reached with treatments of $81.7 \mathrm{~kg} \mathrm{ha}^{-1} \mathrm{P}$ and $1 \mathrm{t} \mathrm{ha}^{-1} \mathrm{CM}$ and $4.3 \mathrm{~kg} \mathrm{ha}^{-1} \mathrm{P}$ and $19 \mathrm{t} \mathrm{ha}^{-1} \mathrm{CM}$, respectively. The highest yield of root dry matter was $0.33 \mathrm{Mg}^{-1}$ obtained with the greatest doses of $\mathrm{P}$ and intermediary doses of $\mathrm{CM}$.
\end{abstract}

Index terms: Medicinal plants, Arctium lappa, fertilization, organic residue.

(Recebido em 5 de novembro de 2007 e aprovado em 20 de agosto de 2008)

\section{INTRODUÇÃO}

A bardana (Arctium lappa L., Asteraceae) é originária da Europa e da Sibéria e chegou ao Brasil por meio dos imigrantes japoneses. Dentre os nomes populares, é conhecida por pega-massa, bardana maior, gobô, orelhade-gigante ou erva dos tinhosos (Font Quer, 1993; Correa Júnior et al., 1994; Alzugaray \& Alzugaray, 1996). Diversos compostos de importância terapêutica já foram isolados da planta e dentre os principais, encontram-se os óleos essenciais (Martins et al., 1998). A planta apresenta atividade hipoglicemiante, depurativa e diaforética. É usada também como cicatrizante, no tratamento de furúnculos, abcessos, acnes, terçol e enfermidades da pele. Da bardana, utilizam-se as raízes, flores e folhas (Santos et al., 1988; Alzugaray \& Alzugaray, 1996; Martins et al., 1998).

As referências sobre os aspectos agronômicos da bardana no Brasil são muito escassas, dificultando o seu

\footnotetext{
'Parte da dissertação apresentada à Universidade Federal de Mato Grosso do Sul (UFMS), pelo primeiro autor, para a obtenção do título de Mestre em Produção Vegetal.

Engenheira Agrônoma, Doutoranda em Produção Vegetal - Faculdade De Ciências Agrárias/FCA - Universidade Federal da Grande Dourados/UFGD Rod. Dourados a Ithaum, Km 12, Zona Rural - Cx. P. 533 - 79804-970 - Dourados, MS - rpgassi@yahoo.com.br

${ }^{3}$ Engenheiro Agrônomo, Doutor em Fitotecnia - Faculdade de Ciências Agrárias/FCA - Universidade Federal da Grande Dourados/UFGD - Rod. Dourados a Ithaum, Km 12, Zona Rural - Cx. P. 533 - 79804-970 - Dourados, MS - nahz@terra.com.br.

${ }^{4}$ Engenheira Agrônoma, Doutor em Fitotecnia - Faculdade De Ciências Agrárias/FCA - Universidade Federal da Grande Dourados/UFGD - Rod Dourados a Ithaum, Km 12, Zona Rural - Cx. P. 533 - 79804-970 - Dourados, MS - mariavieira@ufgd.edu.br

${ }^{5}$ Bióloga, Doutor em Fisiologia Pós-colheita de Frutos e Hortaliças - Faculdade De Ciências Agrárias/FCA - Universidade Federal da Grande Dourados/ UFGD - Rod. Dourados a Ithaum, Km 12, Zona Rural - Cx. P. 533 - 79804-970 - Dourados, MS - silvanascalon@ufgd.edu.br

${ }^{6}$ Engenheiro Agrônomo, Doutor em Fitopatologia - Faculdade de Agronomia e Medicina Veterinária - Universidade de Brasília/UNB - Campus Darcy Ribeiro, Asa Norte, ICC-Sul - Cx. P. 4508 - 70910-970 - Brasília, DF - jkamattos@gmail.com
} 
cultivo que poderia ser uma alternativa para pequenos produtores que procuram diversificar a produção. A adubação mineral e/ou orgânica é um fator estudado que contribui para o aumento da produção de biomassa e princípio ativo nas plantas medicinais. A adubação orgânica é prática recomendada no cultivo de plantas medicinais e tem despertado a atenção dos pesquisadores no Brasil (Ming, 1994; Scheffer \& Côrrea Júnior, 1998; Cruz, 1999). A adubação orgânica aumenta a capacidade de troca catiônica do solo, elevando o pH e reduzindo o teor de alumínio trocável, aumenta a disponibilidade de nutrientes aplicados por meio de fertilizantes minerais e contribui para a sanidade do vegetal por diversificar a produção de substâncias como fenóis e de antibióticos por bactérias (Primavesi, 1982). Vieira et al. (2004), estudando o efeito de doses de cama-de-frango $\left(0,20\right.$ e 40 t ha $\left.^{-1}\right)$ e épocas de colheita $(120,160,200$ e 240 dias após semeio-DAS) na produção de massa seca das raízes da bardana, verificaram que usando-se $40 \mathrm{t} \mathrm{ha}^{-1}$ de cama-defrango, a produção cresceu linearmente durante o ciclo de cultivo, alcançando $385 \mathrm{~kg} \mathrm{ha}^{-1}$ aos 240 DAS.

Em função das características químicas e mineralógicas, os solos tropicais, de modo geral, são ainda extremamente deficientes em fósforo. Consequentemente, o cultivo adequado nesses solos tem na fertilização fosfatada, técnica eficiente para aumentar a produtividade. Principalmente porque a cinética de formação de $\mathrm{P}$ nãolábil em solos de Cerrado é muito rápida (Novais \& Smyth, 1999) e, por isso, nas adubações é o fósforo o nutriente que entra em maiores proporções (Coutinho et al., 1993). Seu fornecimento em dose adequada favorece o desenvolvimento do sistema radicular, aumentando a absorção de água e nutrientes, o P é importante para a formação dos primórdios da partes reprodutivas, é essencial para a boa formação dos frutos e, em geral, incrementa a produção nas culturas (Raij, 1981). Vieira (1995), estudando doses de fósforo e de cama-de-frango no crescimento e produção de mandioquinha-salsa (Arracacia xanthorrhiza Bancroft), verificou que a produção de raízes comercializáveis cresceu linearmente com o aumento das doses de $\mathrm{P}$ e de CF.

Neste trabalho, objetivou-se avaliar o efeito da incorporação ao solo de fósforo e de cama-de-frango de corte semidecomposta sobre o crescimento e a produção da bardana, visando a uma nova alternativa produtiva para pequenos produtores sul-matogrossenses, que procuram diversificar a produção.

\section{MATERIAL E MÉTODOS}

O experimento foi desenvolvido no Horto de Plantas Medicinais (HPM), da Universidade Federal de Mato
Grosso do Sul (UFMS), em Dourados (MS), no período de outubro de 2004 à abril de 2005. O solo originalmente sob vegetação de cerrado é classificado como Latossolo Vermelho distroférrico de textura argilosa e de topografia plana. Os resultados das análises químicas da amostra do solo antes do transplante foram respectivamente: $\mathrm{pH}$ (em água) $=5,5 ; \mathrm{P}=54,0 \mathrm{mg} \mathrm{dm}^{-3} ; \mathrm{K}=10,20 \mathrm{mg} \mathrm{dm}^{-3} ; \mathrm{Mg}=18,60$ $\mathrm{mmol}_{\mathrm{c}} \mathrm{dm}^{-3} ; \mathrm{Ca}=48,00 \mathrm{mmol}_{\mathrm{c}} \mathrm{dm}^{-3} ; \mathrm{Al}^{+3}=1,10 \mathrm{mmol} \mathrm{dm}_{\mathrm{c}} \mathrm{de}^{-3} \mathrm{e}$ Matéria orgânica $=32,10 \mathrm{~g} \mathrm{~kg}^{-1}$. Após a colheita, os resultados das análises químicas da amostra do solo em função dos tratamentos para $\mathrm{pH}$ (em água) e $\mathrm{Al}^{+3}$ (mmol $\mathrm{dm}^{-3}$ ) foram respectivamente: 4,3 e $6(5,9$ e 0,60$) ; 25,8$ e 1 $(5,8$ e 0,6$) ; 25,8$ e $6(5,9$ e 0,6$) ; 25,8$ e 14 (5,9 e 0,6$) ; 43,0$ e 1 $(5,9$ e 0,6$) ; 60,2$ e $6(5,9$ e 0,6$) ; 60,2$ e 14 ( 6,0 e 0,0$) ; 60,2$ e 19 $(6,0$ e 0,0$)$ e $81,7\left(\mathrm{~kg} \mathrm{ha}^{-1}\right)$ e $14\left(\mathrm{t} \mathrm{ha}^{-1}\right)(5,9$ e 0,6$)$. A composição química da cama-de-frango (\%) foi de 29,12; 1,$13 ; 0,63$ e 1,75 para $\mathrm{C}$ orgânico, $\mathrm{P}_{\text {total }}, \mathrm{K}_{\text {total }}$ e $\mathrm{N}_{\text {total }}$, respectivamente e relação $\mathrm{C} / \mathrm{N}=16,64$.

Os fatores em estudo foram cinco doses de fósforo$\mathrm{P}\left(4,3 ; 25,8 ; 43,0 ; 60,2\right.$ e $\left.81,7 \mathrm{~kg} \mathrm{ha}^{-1}\right)$, na forma de superfosfato triplo e cinco doses de cama-de-frango-CF (1; 6; 10; 14 e 19 t ha $\left.^{-1}\right)$, distribuídos a lanço e incorporados com rotoencanteirador ao solo, a uma profundidade de 0$20 \mathrm{~cm}$, um dia antes do transplante. A definição dos tratamentos foi feita pelo uso da matriz experimental Plan Puebla III (Turrent \& Laird, 1975) que resultou nas seguintes combinações de $\mathrm{P}\left(\mathrm{kg} \mathrm{ha}^{-1}\right)$ e de $\mathrm{CF}\left(\mathrm{kg} \mathrm{ha}^{-1}\right)$, respectivamente: 4,3 e $6 ; 25,8$ e $1 ; 25,8$ e $6 ; 25,8$ e $14 ; 43,0$ e 1; 60,2 e 6.; 60,2 e 14; 60,2 e 19 e 81,7 e 14. O delineamento experimental utilizado foi o de blocos casualizados, com nove tratamentos e quatro repetições. Cada parcela teve área de 4,5 $\mathrm{m}^{2}$, com doze plantas arranjadas em fileiras duplas. $\mathrm{O}$ espaçamento entre plantas foi de $0,50 \mathrm{~m}$ e entre fileiras de $0,54 \mathrm{~m}$. Para a propagação da bardana foram usadas sementes colhidas de plantas cultivadas no Horto de Plantas Medicinais da UFMS. As mudas foram produzidas inicialmente em bandejas de poliestireno, com substrato Plantmax HA, sob tela de nylon com 50\% de sombreamento, em temperatura ambiente. Após 30 dias da semeadura, as mudas foram repicadas para sacos plásticos com capacidade para $500 \mathrm{~g}$, enchidos com substrato preparado com três volumes de terra, um de cama-defrango semidecomposta e um de areia grossa. Quando as plântulas atingiram cerca de $0,15 \mathrm{~m}$ de altura, cerca de 58 dias após a semeadura foram transplantadas para o local definitivo. Os tratos culturais compreenderam irrigações feitas por aspersão, a cada dois dias, e capinas com enxadas, sempre que necessárias.

Durante o ciclo de cultivo, foram medidas as alturas de todas as plantas das parcelas, a cada dez dias, a partir 
de 60 até 120 dias após o transplante. Na colheita, as plantas foram colhidas inteiras com enxadão, e depois separadas as folhas e raízes e, posteriormente, pesadas para determinação da massa fresca. Para obter a massa seca, os materiais vegetais foram seccionados manualmente e colocados em estufa com circulação forçada de ar, a $60^{\circ} \pm$ $5^{\circ} \mathrm{C}$, até massa constante.

Às médias dos dados de altura das plantas foram ajustadas equações de regressão, com emprego de polinômios ortogonais. Os dados de produção foram submetidos à análise de variância para determinação do erro experimental da matriz. Para estimar as superfícies de resposta, foram ajustados os modelos quadrático e quadrático base raiz quadrada às médias por tratamento. Cada componente dos modelos foi testado até $5 \%$ de probabilidade, pelo teste $\mathrm{F}$, tendo sido utilizado o quadrado médio do erro experimental da matriz. Cada efeito individual do modelo escolhido foi testado até o nível de 5\%, pelo teste F, corrigido em função do erro experimental, usando t calculado pelo programa estatístico SAEG (Alvarez Venegas, 1991; Ribeiro Júnior, 2001).

\section{RESULTADOS E DISCUSSÃO}

O padrão de crescimento em altura apresentou efeito quadrático, exceto para o tratamento $60,2 \mathrm{~kg} \mathrm{ha}^{-1}$ de fósforo$\mathrm{P}$ e $6 \mathrm{t} \mathrm{ha}^{-1}$ de cama-de-frango-CF, com taxas diferentes entre os tratamentos durante o período em estudo (Figura 1). A altura máxima $(129,87 \mathrm{~cm})$ alcançada aos 113 dias após o transplante foi observada no tratamento onde se combinou $60,2 \mathrm{~kg} \mathrm{ha}^{-1}$ de P e $14 \mathrm{t} \mathrm{ha}^{-1} \mathrm{de} \mathrm{CF}$. A menor altura das plantas $(70,63 \mathrm{~cm})$, aos 120 dias após o transplante, foi obtida com o uso da dose $25,8 \mathrm{~kg} \mathrm{ha}^{-1}$ de $\mathrm{P}$ combinada com $1 \mathrm{t} \mathrm{ha}^{-1} \mathrm{de} \mathrm{CF}$

Pelos resultados obtidos pode-se observar o efeito positivo do $\mathrm{P}$ com a CF sobre a altura das plantas, mostrando que, provavelmente, houve aumento da solubilização do P no solo, tornando assim, o nutriente mais disponível para as plantas (Kiehl, 1993). Os tratamentos testados se ajustaram ao modelo quadrático, exceto com o uso de 60,2 e $6 \mathrm{t} \mathrm{ha}^{-1}$ de $\mathrm{P}$ e cama-de-frango, o qual se ajustou ao modelo linear. Esses resultados são diferentes daqueles obtidos por Vieira et al. (2004), que observaram crescimento linear na altura das plantas, no mesmo local, mas com período em estudo (março a dezembro) diferentes, de forma que essa diferença no padrão de crescimento entre os experimentos possa ser atribuída, provavelmente, às diferenças climáticas características do período em que foram conduzidos os

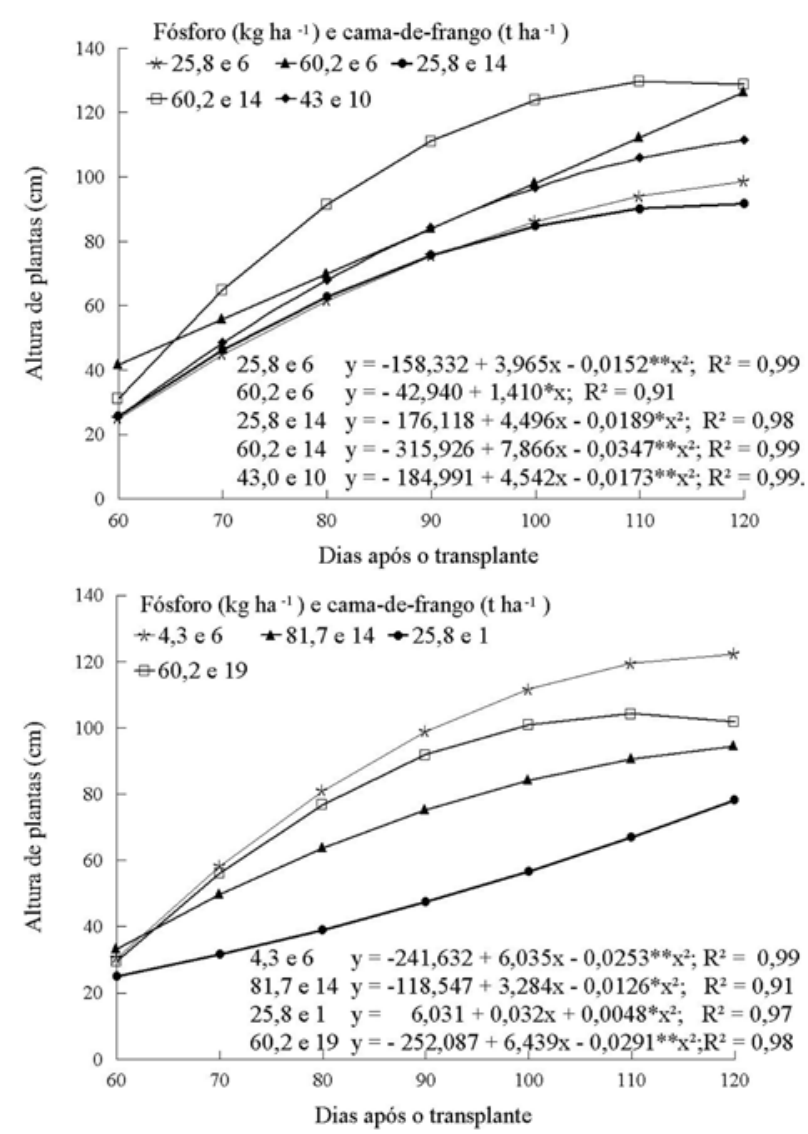

Figura 1 - Altura das plantas da bardana em função de dias após o transplante e do uso de P e de cama-de-frango em diferentes doses. Dourados, UFMS, 2004-2005.

experimentos, onde foram verificadas no experimento atual, altas temperaturas e precipitações.

As maiores produções de massa fresca das folhas (Figura 2) foram de 22,87 $\mathrm{Mg} \mathrm{ha}^{-1}$ quando se utilizou a dose de $81,7 \mathrm{~kg} \mathrm{ha}^{-1}$ de $\mathrm{P}$ e de $18,38 \mathrm{Mg} \mathrm{ha}^{-1}$ com a dose de $19 \mathrm{t} \mathrm{ha}^{-1} \mathrm{de} \mathrm{CF}$. Apesar do alto teor de P inicialmente observado no solo, ainda pode-se observar resultados positivos relacionados às doses crescentes de $\mathrm{P}$ para a produção de massa fresca das folhas, isso se deve, provavelmente, ao fato dos solos brasileiros apresentarem baixa disponibilidade desse elemento, passando assim a ser um dos nutrientes com maior resposta pelas plantas (Novais \& Smyth, 1999). O efeito positivo com o resíduo orgânico, provavelmente foi decorrente do aumento de macro e micronutrientes disponíveis no solo para as plantas, redução do alumínio trocável e da fixação do fosfato, de forma que a matéria orgânica do solo libera parte do $\mathrm{N}$ e $\mathrm{P}$, promovendo incrementos na produção (Kiehl, 1993). 


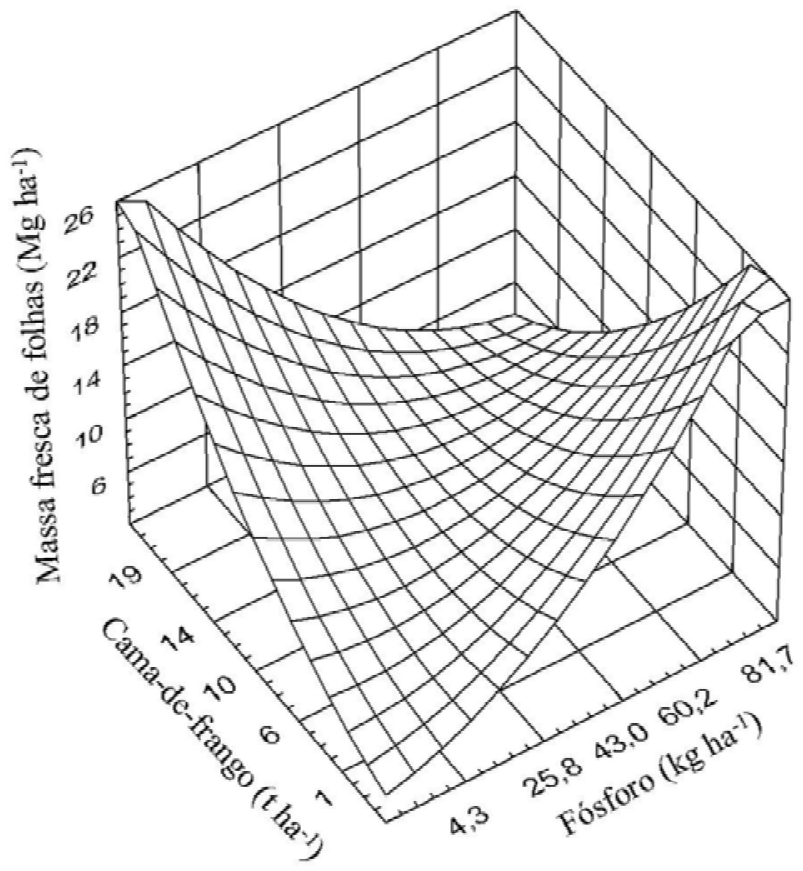

Figura 2 - Massa fresca de folhas da bardana em função de doses de P e cama-de-frango. (C.V. $=40,37 \%$ ). Dourados, UFMS, 2005. $\hat{y}=5374,48+66,5046 \mathrm{P}+$ $0,245267 \mathrm{CF}+2,03101 * \mathrm{P}^{2}+0,00002718089 \mathrm{CF}^{2}-$ $0,0216329 * \mathrm{PCF} ; \mathrm{R}^{2}=0,63 *$ significativo a $5 \%$ de probabilidade.

Na produção de massa seca das folhas, observouse acréscimos à medida que se aumentaram as doses de cama-de-frango e pouca influência das doses de P (Figura 3 ). Resultados estes foram semelhantes aos encontrados por Vieira et al. (2004) que, estudando três doses de camade-frango (0; 20 e $\left.40 \mathrm{t} \mathrm{ha}^{-1}\right)$, observaram aumento linear da produção da massa seca das folhas da bardana em relação às doses crescentes da cama-de-frango utilizada. De acordo com Larcher (2000), vários fatores influenciam a produção de massa seca, como: irrigação, temperatura e oferta de nutrientes. Portanto, maiores doses da cama-de-frango, favoreceram a produção de fotoassimilados e de massa seca. Isso porque o princípio básico das plantas anuais é usar a maior proporção dos fotossintatos para a formação das folhas, as quais participam da produção e aumentam a absorção da planta, como consequência, desenvolvem esses órgãos preferencialmente (Larcher, 2000). A ausência de resposta a fósforo das plantas de bardana, pode deverse ao fato de não se conhecer as exigências nutricionais dessa hortaliça e de ter sido utilizado um solo corrigido e que vem sendo usado, por vários anos, para implantação de experimentos com hortaliças, e daí as $54,0 \mathrm{mg} \mathrm{dm}^{-3} \mathrm{de} P$ detectadas pela análise do solo, podem ser consideradas elevadas para a maioria de solos sob vegetação de cerrado, como os utilizados por Vieira (1995), e por isso a adubação fosfatada não proporcionou resposta positiva para algumas características avaliadas das plantas de bardana.

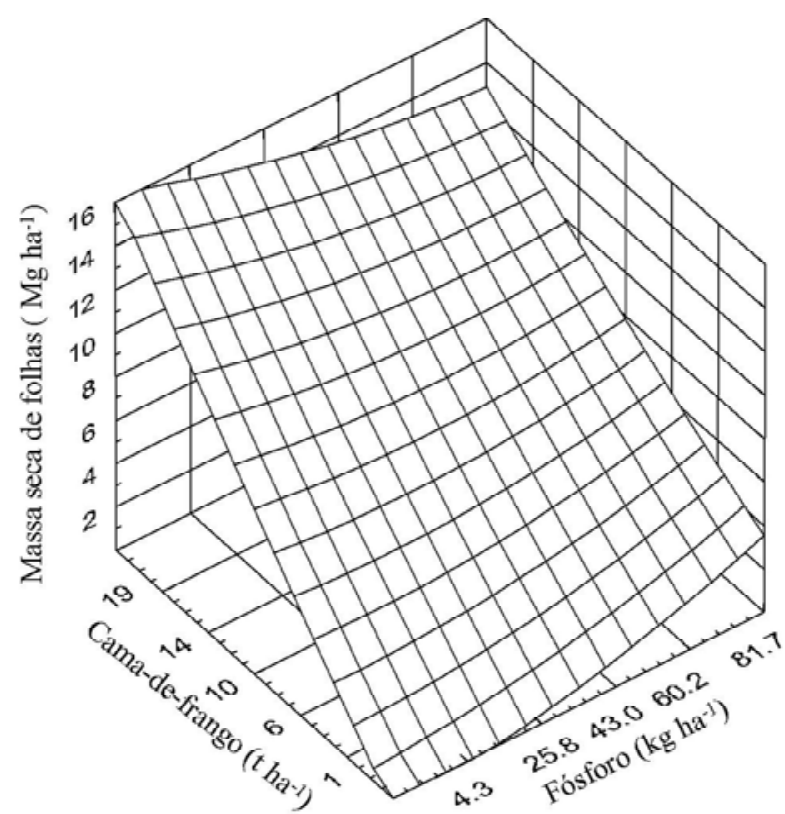

Figura 3 - Massa seca de folhas da bardana em função de doses de P e de cama-de-frango. (C.V. $=31,07 \%$ ). Dourados, UFMS, 2005. $\hat{\mathrm{y}}=882,115+12,4814 \mathrm{P}+0,625342 \mathrm{CF}+$ $0,272866 \mathrm{P}^{2}+0,00000265607 \mathrm{CF}^{2}-0,00322044$ *PCF; $\mathrm{R}^{2}$ $=0,71 *$ significativo a $5 \%$ de probabilidade.

As maiores produções de massas frescas de raízes foram de 2,44 $\mathrm{Mg} \mathrm{ha}^{-1}$ e 2,00 $\mathrm{Mg} \mathrm{ha}^{-1}$, alcançadas com os tratamentos $81,7 \mathrm{~kg} \mathrm{ha}^{-1}$ de P e $1 \mathrm{t} \mathrm{ha}^{-1}$ de CF e 4,3 $\mathrm{kg}^{-}$ de P e $19 \mathrm{t} \mathrm{ha}^{-1}$ de CF, respectivamente (Figura 4). Por isso, a maior produção de raízes de bardana com muito $\mathrm{P}$ pode ter resultado de suas funções como regulador do fósforo inorgânico na fotossíntese, no metabolismo de carboidratos, na relação amido/sacarose nas folhas e na partição de fotoassimilados entre as folhas (fonte) e órgãos de armazenamento (dreno) (Marschner, 1995). A matéria orgânica da cama-de-frango deve ter ativada aos processos microbianos, fomentando, simultaneamente, a estrutura, a aeração e a capacidade de retenção de água no solo (Silva Júnior \& Siqueira, 1997), assim a maior dose (19 $\mathrm{t} \mathrm{ha}^{-1}$ ) de cama-de-frango utilizada, favoreceu o desenvolvimento do sistema radicular, aumentando a 
absorção de água e de nutrientes e, consequentemente, a produção das raízes.

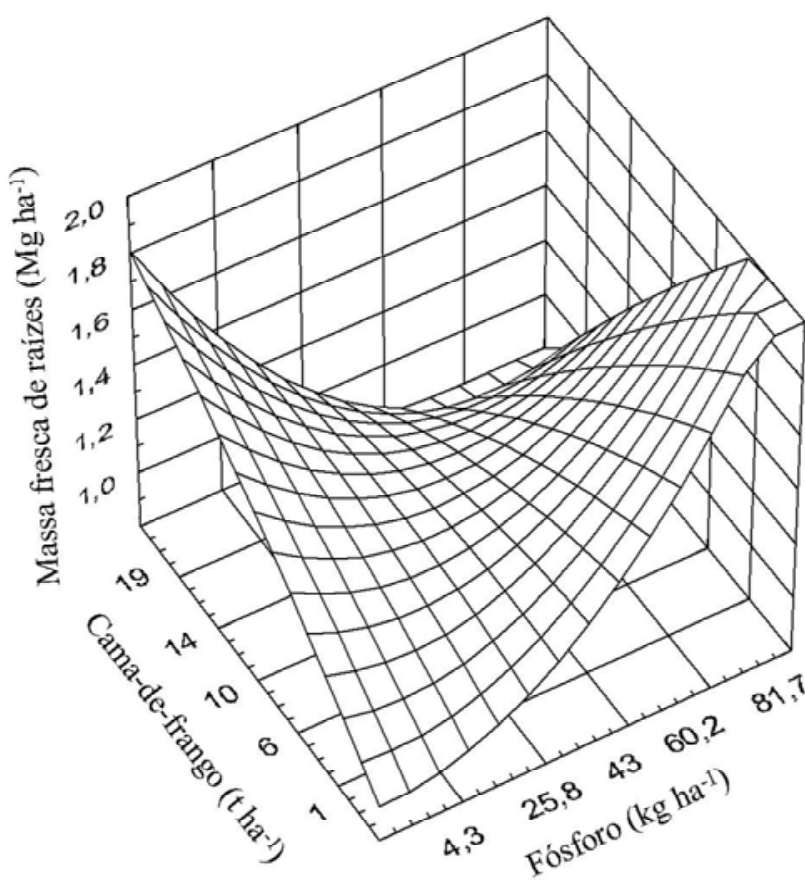

Figura 4 - Massa fresca de raízes da bardana em função de doses de P e cama-de-frango. (C.V. = 23,59\%). Dourados, UFMS, 2005. $\hat{\mathrm{y}}=396,513+25,9381 \sqrt{\mathrm{P}}+12,9881 * \sqrt{\mathrm{CF}}+$ $29,2089 * * \mathrm{P}+0,034848 \mathrm{CF}-3,59414 * * \sqrt{\mathrm{P}} \sqrt{\mathrm{CF}} ; \mathrm{R}^{2}=0,58 *$ $\mathrm{e}^{* *}$ significativo a 5 e $1 \%$ de probabilidade respectivamente.

A maior produção de massa seca de raiz foi $0,33 \mathrm{Mg}$ ha $^{-1}$ obtida com o uso das maiores doses de fósforo e doses intermediárias de cama-de-frango (Figura 5), mostra o efeito benéfico da associação de adubos minerais fosfatados com orgânicos. Segundo Novais \& Smyth (1999) a deficiência de fósforo é o fator mais limitante ao desenvolvimento das plantas em solos de cerrado, não só pelos baixos níveis naturais, mas também pela grande capacidade de fixação desses solos, como consequência da acidez e de elevados teores de óxidos de ferro e alumínio. A aplicação de resíduo orgânico pode ter aumentado a disponibilidade de fósforo às plantas, pois aumenta a produção de gás carbônico no solo, solubilizando o fosfato mineral; pela formação do complexo humo-fosfato; pela remoção de bases dos fosfatos insolúveis pelos quelados da matéria orgânica; pelo revestimento dos sesquióxidos de ferro e alumínio pelo húmus, evitando assim a fixação do fósforo solúvel (Kiehl, 1993).

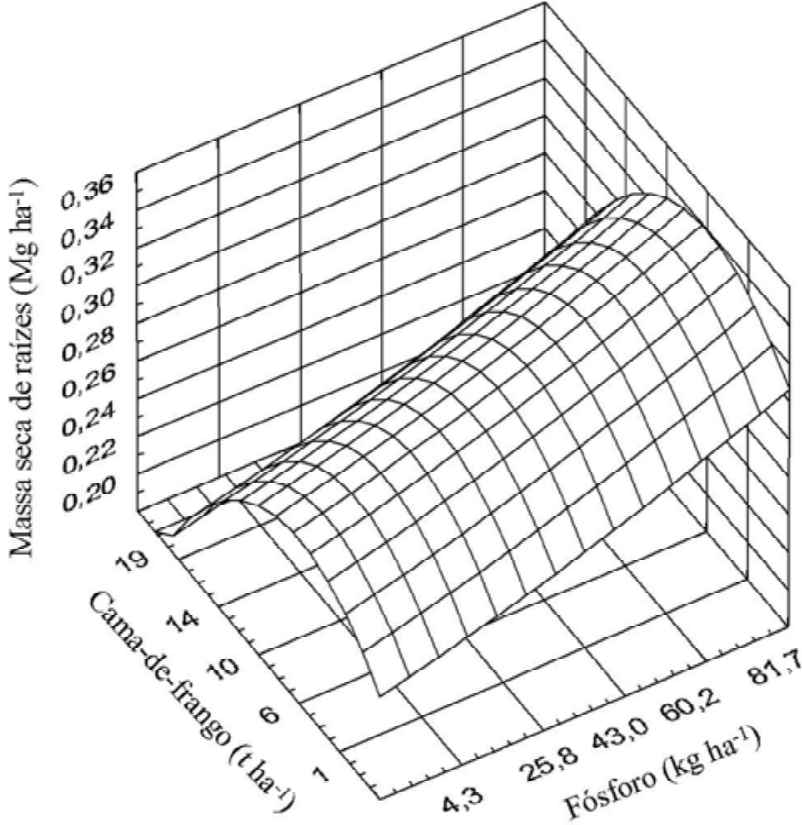

Figura 5 - Massa seca de raízes de bardana em função de doses de P e cama-de-frango. (C.V. $=21,28 \%$ ). DouradosUFMS, 2005. $\hat{y}=254,407+0,56016 \mathrm{P}+0,00611549 \mathrm{CF}+$ $0,00199633 \mathrm{P}^{2}-0,000000504289 * * \mathrm{CF}^{2} \mathrm{R}^{2}=0,44$

$* *$ significativo a $1 \%$ de probabilidade.

\section{CONCLUSÃO}

Nas condições em que foi conduzido o experimento:

O P e a cama-de-frango, isoladamente, possibilitaram a obtenção das maiores produções de massa fresca e seca da parte aérea, massa fresca de folhas e raízes da bardana. As maiores doses de cama-de-frango-CF, independente das doses de fósforo-P, resultaram nas maiores produções de massa seca das folhas da bardana. As maiores produções de massas secas das raízes foram obtidas com as maiores doses de $\mathrm{P}$ e doses intermediárias de $\mathrm{CF}$.

\section{AGRADECIMENTOS}

À CAPES, pela concessão da bolsa de mestrado, ao $\mathrm{CNPq}$, pelas bolsas de produtividade em pesquisa e à FUNDECT, pelo apoio financeiro.

\section{REFERÊNCIAS BIBLIOGRÁFICAS}

ALVAREZ VENEGAS, V.H. Avaliação da fertilidade do solo: superfícies de resposta: modelos aproximativos para expressar a relação fator-resposta. Viçosa, MG: UFV, 1991. 75p. 
ALZUGARAY, D.; ALZUGARAY, C. Plantas que curam. São Paulo: Ed. Três, 1996. v.1, 260p.

CORREA JÚNIOR, C.; MING, L.C.; SCHEFFER, M.C. Cultivo de plantas medicinais, condimentares e aromáticas. Curitiba: Emater, 1994. 94p.

COUTINHO, E.L.M.; NATALE, W.; SOUZA, E.C.A. de. Adubos e corretivos: aspectos particulares na olericultura. In: SIMPÓSIO SOBRE NUTRIÇÃO E ADUBAÇÃO DE HORTALIÇAS, 1990, Jaboticabal, SP. Anais... Piracicaba: Potafós, 1993. p.85-140.

CRUZ, R.B.G. Desenvolvimento de sistema de cultivo para hortelã-rasteira (Mentha $\boldsymbol{x}$ villosa Huds.). 1999. 35f. Dissertação (Mestrado em Fitotecnia)-Universidade Federal do Ceará, Fortaleza, 1999.

FONT QUER, P. Plantas medicinales: el dioscórides renovado. Madrid: Labor, 1993. v.3, 1033p.

KIEHL, E.J. Fertilizantes organominerais. Piracicaba: Agronômica Ceres, 1993.

LARCHER, W. Ecofisiologia vegetal. São Carlos: RimaArtes e Textos, 2000. 531p.

MARSCHNER, H. Mineral nutrition of higher plants. London: Academic, 1995. 674p.

MARTINS, E.R.; CASTRO, D.M. de; CASTELLANI, D.C.; DIAS, J.E. Plantas medicinais. 2.ed. Viçosa, MG: UFV, 1998. 220p.

MING, L.C. Estudos e pesquisas de plantas medicinais na agronomia. Horticultura Brasileira, Brasília, v.12, n.1, p.3-9, 1994.

NOVAIS, R.F.; SMYTH, T.J. Fósforo em solo e planta em condições tropicais. Viçosa, MG: UFV, 1999. 399p.
PRIMAVESI, O. Fatores limitantes da produtividade agrícola e plantio direto. São Paulo: BASF, 1982. 56p.

RAIJ, B. van. Avaliação da fertilidade do solo. Piracicaba: Instituto da Potassa \& Fosfato, 1981. 120p.

RIBEIRO JÚNIOR, J.I. Análises estatísticas no SAEG. Viçosa, MG: UFV, 2001. 301p.

SANTOS, C.A.M.; TORRES, K.R.; LEONART, R. Plantas medicinais: herbarium, flora et scientia. 2.ed. Curitiba: Scientia et Labor, 1988. 160p.

SCHEFFER, M.C.; CORRÊA JÚNIOR, O. Mercado de plantas medicinais. In: JORNADA CATARINENSE DE PLANTAS MEDICINAIS-SAÚDE E

SUSTENTABILIDADE PARA O $3^{\circ}$ MILENIO, 1., 1988, Tubarão, SP. Anais... Tubarão: UNISUS, 1998. p.102-108.

SILVA JÚNIOR, J.P. da; SIQUEIRA, J.O. Aplicação de formononetina sintética ao solo como estimulante da formação de micorriza no milho e na soja. Revista Brasileira de Fisiologia Vegetal, Brasília, v.9, n.1, p.3541, 1997.

TURRENT, A.; LAIRD, R.J. La matriz PLAN PUEBLA, para ensayos sobre prácticas de producción de cultivos. Agrociência, Pelotas, v.19, p.117-143, 1975.

VIEIRA, M.C. Avaliação do crescimento, da produção de clones e efeito de resíduo orgânico e de fósforo em mandioquinha-salsa no Estado de Mato Grosso do Sul. 1995. 146f. Tese (Doutorado em Fitotecnia)-Universidade Federal de Viçosa, Viçosa, MG, 1995.

VIEIRA, M.C.; RAMOS, M.B.M.; HEREDIA ZÁRATE, N.A.; TEIXEIRA, I.R.; FERNANDES, R.de S. Produção da bardana sob diferentes doses de cama-de-frango e épocas de colheita. In: CONGRESSO BRASILEIRO DE OLERICULTURA, 44., 2004, Campo Grande, MS.

Resumos... Campo Grande: UNIDERP, 2004. CD-ROM. 